\title{
Values held by young stakeholders on financial planning regarding liabilities for nuclear decommissioning
}

\author{
B. Labor ${ }^{1} \&$ S. Lindskog ${ }^{2}$ \\ ${ }^{1}$ Badania Dydaktyczne, Poland \\ ${ }^{2}$ The Swedish Radiation Safety Authority, Sweden
}

\begin{abstract}
Nuclear waste programmes have from time to time encountered set-backs related to lack of trust from society. One experience is that it is necessary that all nuclear work be conducted in accordance with high standards on health and the environment, including funding for future environmental liabilities according to the Polluter Pays Principle (PPP). Another experience is that it is imperative to communicate with the stakeholders, and to understand the reasons for their positions.

Surveys on opinions have usually been based on response by letter and similar. In particular for young stakeholders, this has implied very low response rates and associated low validities of the results. The present work is based on an experimental programme with altogether 880 personal interviews in three towns in Poland with a near $100 \%$ response rate.

The conclusions include the following:

- sustainable energy sources are favoured (nuclear power is one option);

- the values are based on safety and environmental aspects;

- the Polluter Pays Principle is to be honoured;

- there is a scepticism concerning the will and capability of present decision makers to implement this principle;

- there is too little basis for educated opinions;

- there is no difference between the sexes;

- it is necessary to use more comprehensive communication channels.
\end{abstract}

Keywords: nuclear, decommissioning, dismantling, radioactivity, environmental, liability, fund, cost calculation, stakeholders, values. 


\section{Background}

A large number of nuclear facilities - including nuclear power plants, research reactors and various other nuclear facilities - are approaching the end of their economic as well as technical life times, and will therefore enter the decommissioning phase during the present decade. Such facilities are contaminated with radioactive material and frequently also activated, and their decommissioning represents huge environmental liabilities. It is therefore pertinent that sufficient financial resources to cover all future costs be accumulated by the generation reaping the benefits from nuclear power production.

The task to make allowances for future costs is governed by the Polluter Pays Principle (PPP). However, the calculations must be of such quality that they are generation-neutral, and funding compliant to the Extended Polluter Responsibility (EPR). It is occasionally put forward that conventional economic analysis tends to treat future generations unfairly [1], i.e. tends to underestimate future costs. Complex environmental liability situations include long operation and decommissioning times and often concern more than one generation. Here, implementation of the EPR principle implies that the "property rights" of future generations must be fully respected and acknowledged in the financial systems for funding of decommissioning and dismantling of nuclear facilities. One key step to meet this daunting task is to safeguard and assure that appropriate financial resources are accumulated in segregated funds such that no financial liabilities are passed on to future generations.

In Sweden, for example, such an approach has been formalised in a new ordinance that came into force on November 1, 2008. It states that all environmental liabilities for future decommissioning and associated waste management must be assessed and declared, and that funding must be secured to cover the estimated future environmental liabilities. The estimation must be in concordance with good accounting practice. This means that, in general, the error in the estimates may diverge by not more than $\pm 15 \%$ [2].

\section{The strive for enhanced efficiency}

The long term process to manage the decommissioning of nuclear facilities and the associated waste can be seen as a general efficiency maximisation problem that is subject to constraints. These constraints comprise not only conventional techniques, including associated contemporary research and development, but also include social questions and especially financial and democratic issues. The social aspects need to be addressed in an open and transparent manner in order to enable a sound earning of support from the general public. Such a support should be based on a sustainability and long term credibility of nuclear waste liabilities as well as planning and implementation of decommissioning and dismantling of nuclear facilities.

The key to success in defining and establishing such a system, in which these constrains are fully considered, is earning long-term support from the general 
public. The strategic importance of this issue was realised when commercial nuclear power was introduced in Sweden. This lead to the issuing of the Financing Act, which with only moderate adjustments is in force still today.

One major threat to the system is that costs may exceed what has been budgeted and funded. It has proven notoriously difficult to obtain reliable estimates, primarily due to specific cost driving factors linked to critical features and events.

In some other countries, major set-backs have occurred so that the nuclear waste programmes have been delayed, redirected or halted. Such events are of course related to the presence of well functioning democratic processes, and are also of critical importance for achieving full legitimacy for the implementations of proposed methods and techniques for nuclear waste management.

From the perspective of financial control and efficiency, such set-backs may lead to consumption of more financial resources than in an optimal case. Adverse developments might be mitigated by improving the quality of the cost estimates and the planning process such that set-backs are either controlled or reduced to a minimum. From the perspective of efficiency, there is also strong support to accept and implement the Extended Polluter Responsibility (EPR) principle so that the inter alia rights of future generations are taken into consideration already from the early phases of cost estimating and decommissioning planning. In this process, the inclusion of the younger generation can be seen as a resource that can contribute to a good efficiency.

\section{The inclusion of the public}

The Swedish system may be used as an example of how enhanced public inclusion and how good application of associated methods (e g for conflict reduction) may contribute to more efficient processes. During the last 20 years there have been some major activities for public dialogue and risk communication between stakeholders [3-6]. The Swedish system has, for instance, given non-governmental organisations opportunities to participate in the planning for final disposal, and thereby broadened the democratic base of the project. One common weakness of these projects is, however, that they have not been based on the Extended Polluter Responsibility (EPR) principle, and therefore inter alia have not been successful in including younger generations.

It is generally accepted that decommissioning strategies will vary according to a number of considerations. Hence, it is for example anticipated that the accessibility and availability of waste disposal alternatives, the quality of radiological mapping, the radiation protection policy, cost and funding considerations and local site factors are highly significant for the process of defining the general prerequisites for efficient decommissioning strategies. In this context, the significance of the choice of methodology for communication of decommissioning strategy needs to be identified and evaluated at a first step, see for example [3, 4, 7 (pp. 9-19)]. The aim is to reduce the risks for delays in the decommissioning phase and thus to alleviate challenges which would otherwise 
demand increased expenditure and specialist knowledge as the conditions of facilities decay and deteriorate, see for example [7 (pp. 7-19)-9].

The collection of comprehensive and authentic data about the values of younger stakeholders may help the present generation to bridge the gap between the planning of the present generation for the long term safe management of nuclear waste and the financial abilities of future generations to implement the plans. Such data and knowledge may, in turn, help us to find better and more appropriate socially constructive forms for inclusion of younger stakeholders at an early stage. This will enhance our abilities to design platforms for sustainable communication with all stakeholder groups. It may also contribute to enhancing the efficiency in the planning process and final decommissioning decisions since the younger stakeholders of today will most likely be the actual decision makers. The failure to incorporate the views of younger stakeholders in the planning and cost calculations may well prove to be a cost raiser. It is prudent practice to base current cost calculations on such robust assumptions that ensure that any myopia of the present generation is taken into consideration. For such prudent practice, it is pertinent to compile and make use of the values of younger stakeholder.

\section{The values of younger citizens}

The intrinsic properties of projects of decommissioning and dismantling with their trans-generational characteristics and associated longitudinal base call for an early inclusion of stakeholders. The interaction with groups in the local municipality is highly significant for the successful planning and completion of a project. Issues such as overall political prerequisites and national interests call for an open and transparent flow of information also on the national level.

The inclusion of all stake holder groups is essential. It must be stressed, however, that the opportunity to include the younger citizens at an early stage in the democratic decision making process provides a unique possibility to gain commitment and support from a future group of stakeholders already today. In this way, unnecessary and time consuming reproduction of processes can be avoided.

In the past, our ability to make conclusions in this area has been severely limited by the low levels of response frequencies. In addition, the answers have been inconsistent, thus reflecting disturbances in the communication process.

One common feature of the previous studies is the use of the same batteries of questions together with identical layouts of the questionnaires for all age groups. This may well explain the low response frequencies as well as the questionable quality of the answers. It is well known that young persons communicate by SMS and e-mail rather than letters in the ordinary mail, as opposed to older people. It can thus be readily predicted that the response frequency will be low for young people. On the other hand, if a more experimental model for data gathering is used for the younger stakeholders, it can be predicted that the response rate is higher [10]. Hence, such considerably higher response frequencies can be expected in cases where data retrieval is done in authentic 
environments where advantage is taken of comprehensive knowledge about learning processes.

Authentic data for Swedish conditions from a county with nuclear power have been collected in an explorative study in Kalmar in 2007 [11]. It can be expected, however, that the attitudes in a county with nuclear power may differ substantially from those of a county without nuclear power.

This need for more generally valid information has prompted the present survey which is from the neighbouring country Poland. It has no nuclear power plants, but a vivid national dialogue on building such plants. The conditions in Poland are thus close to ideal for obtaining "bench-marked" data of the values of younger citizens regarding decommissioning for the purpose of comparison.

\section{The survey data}

The scope of the present paper is to present some results from the above mentioned survey based on an experimental design, and to analyse this material with regard to the attitudes of younger people towards decommissioning and nuclear waste $[12,13]$. The data was collected as a stratified sample during January to November 2008 in the Polish towns of Gdansk, Lublin and Elblag, and the numbers of responses are shown in Table 1.

Table 1: $\quad$ The number of responses in the survey.

\begin{tabular}{|c|c|c|c|c|c|}
\hline $\begin{array}{c}\text { City } \\
\text { Gender }\end{array}$ & Gdansk & Elblag & Lublin & Total & $\%$ \\
\hline Men & 249 & 38 & 105 & 392 & $50,30 \%$ \\
\hline Woman & 119 & 89 & 180 & 388 & $49,70 \%$ \\
\hline Total & 368 & 127 & 285 & 780 & $100,00 \%$ \\
\hline
\end{tabular}

\section{The Swedish case}

The Ågesta electricity and district heat producing heavy water nuclear power reactor in the outskirts of Stockholm was shut down in 1973. The two light water nuclear power reactors at Barsebäck near Malmö were shut down in 1999 and 2004 , respectively. The large $\left(50 \mathrm{MW}_{\text {th }}\right)$ research reactor at Studsvik, $100 \mathrm{~km}$ south of Stockholm, was shut down in the year 2005. At present, the decommissioning of these reactors is in a transition phase pending access to space for final disposal of long-lived low and intermediate level waste which is anticipated to be available at the beginning of the 2020's.

Thus, the extent of the transition period, i.e. the time elapsed between the final shutdown and the last day of the dismantling, can be estimated to be at least one generation.

This implies that it will be the next (or some successive) generation that will be responsible for the decommissioning and the associated waste management. Thus, the younger citizens are, and will be, stakeholders for a long time. In an 
increasingly unified Europe, this may concern not only Sweden but also (what is presently) other countries.

\section{Summary of the results from the survey}

A summary of the findings of the survey is presented below in Sections 7.1 7.7. Details of the study can be found in $[12,13]$. A general finding is that the differences between the sexes as well as those between the three towns are insignificant.

\subsection{The energy mix preferences}

In the aggregated survey data, a total of 780 students gave 1123 answers on the multiple answers question: Which form of energy do you prefer? In total, 35\% declared that they prefer windmills. Hydro power was said to be preferred by $32 \%$ followed by nuclear power that was regarded as preferable by $25 \%$. Energy produced by coal was seen as an acceptable option for as little as $2,8 \%$.

The survey data supports the view that younger stakeholders are in favour of renewable and long-term sustainable energy sources vis-à-vis non-renewable counterparts. Here it is perceived that hydro power and wind power, e.g. windmills, are the two most popular energy sources. At the same time it may be envisaged that as much as $1 / 4$ are accepting nuclear power as a future potential energy supply mode. Further details are presented in Table 2.

Table 2: Which form of energy do you prefer?

\begin{tabular}{|c|c|c|c|c|c|c|c|c|c|c|c|}
\hline \multirow{2}{*}{ Answer } & City & \multicolumn{2}{|c|}{ Gdansk } & \multicolumn{2}{|c|}{ Elbląg } & \multicolumn{2}{c|}{ Lublin } & \multicolumn{2}{c|}{ Sub SUM } & \multicolumn{2}{|c|}{ SUM } \\
\cline { 2 - 13 } & Gender & $\mathrm{M}$ & $\mathrm{W}$ & $\mathrm{M}$ & $\mathrm{W}$ & $\mathrm{M}$ & $\mathrm{W}$ & $\mathrm{M}$ & $\mathrm{W}$ & MW & $\%$ \\
\hline Coal & 8 & 13 & 1 & 4 & & 5 & 9 & 22 & 31 & 2,8 \\
\hline Nuclear Power & 72 & 19 & 18 & 16 & 78 & 80 & 168 & 115 & 283 & 25,2 \\
\hline Hydro Power & 106 & 44 & 16 & 40 & 60 & 97 & 182 & 181 & 363 & 32,3 \\
\hline Windmills & 111 & 61 & 21 & 53 & 52 & 99 & 184 & 213 & 397 & 35,4 \\
\hline Miscellaneous & 9 & 4 & & 2 & 16 & 18 & 25 & 24 & 49 & 4,4 \\
\hline Total & 297 & 137 & 56 & 113 & 206 & 299 & 568 & 555 & 1123 & 100 \\
\hline
\end{tabular}

\subsection{The implicit application of the Polluter Pays Principle}

A total of 786 students answered the question: Who shall take care of the Swedish nuclear waste? As many as $88 \%$ answered that they thought that Sweden should take care of its nuclear waste. This answer clearly indicates that the younger stakeholders have a firm belief in the Polluter Pays Principle (PPP).

Only $12 \%$ of the students held the opinion that the nuclear waste generated in Sweden might be managed also elsewhere within the European Union. Such a view does not necessarily imply a breach of the PPP principle since the polluter might still pay the full costs. 
The conclusion is that the data strongly indicates that the Polluter Pays Principle has a solid foundation among the younger European citizens.

\subsection{Younger stakeholders and the decision makers}

On the question: Do you have confidence and trust in the decisions makers' capability in the decommissioning process? the distribution of the answers was an almost perfect image of an Erlangen distribution, see [12].

In the cluster samples $18 \%$ gave the response that they trust the decision maker's determinations and commitments as well as their ability to solve the problem of final storage of radioactive waste from decommission of nuclear power plants, including planning, construction and operation. Furthermore, 26\% gave the answer that they had some kind of mistrust in the decision maker's commitments on this matter. The bulk of respondents, $57 \%$, declared that they did not have a clear position in this matter, and that they were unsure about how to respond. Further detail is provided in Table 3.

Table 3: Do you have confidence and trust in the decisions makers' capability in the decommissioning process?

\begin{tabular}{|c|c|c|c|c|c|c|c|c|c|c|c|}
\hline \multirow{2}{*}{ Answer } & City & \multicolumn{2}{|c|}{ Gdansk } & \multicolumn{2}{|c|}{ Elbląg } & \multicolumn{2}{c|}{ Lublin } & \multicolumn{2}{|c|}{ Sub SUM } & \multicolumn{2}{|c|}{ SUM } \\
\cline { 2 - 13 } & Gender & M & W & M & W & M & W & M & W & MW & $\%$ \\
\hline Yes & 37 & 29 & 8 & 8 & 34 & 23 & 79 & 60 & 139 & 17,8 \\
\hline Do not / unsure & 135 & 58 & 19 & 56 & 55 & 120 & 209 & 234 & 443 & 56,7 \\
\hline \multicolumn{2}{|c|}{ No } & 77 & 33 & 11 & 25 & 16 & 37 & 104 & 95 & 199 & 25,5 \\
\hline Total & 249 & 120 & 38 & 89 & 105 & 180 & 392 & 389 & 781 & 100 \\
\hline
\end{tabular}

\subsection{Propensity to live in the vicinity of a final storage for nuclear waste}

The reason to pose the question, Can you consider having a site for final disposal of nuclear waste near to your home? to the respondents was to evaluate the propensity to live in the vicinity of a nuclear waste final storage facility. Less than $20 \%$ - or 152 out of a total of 781 of the students - said that they could consider this. Consequently, over $80 \%$ were against having a nuclear waste site near to their homes.

\subsection{The platform of the younger stakeholder's opinions}

The values that the younger stakeholders' base their views on are summarised in Table 4 . In the samples, a total of $15 \%$ expressed that their opinions were based on trust for the stakeholders involved. Another $12 \%$ said that their opinions were based on the opportunities, both financial and social, linked to major decommissioning projects. Almost one third, 29\%, expressed that their opinions were based on insufficient knowledge. More than one third, 38\%, said that their opinion was based on uneasiness about the risks involved. A small group comprising $6 \%$ gave other reasons for their views. 
The data shows that around two thirds of the younger citizens base their values on the risks associated with the handling of nuclear waste together with lack of knowledge.

The value base also includes trust for the involved stakeholders which accounts for around one fifth to one sixth of the explanation as well as opportunities linked to a disposal of nuclear waste for around one tenth of the explanation value.

The data suggests that younger citizens base their values mainly on fundamental questions concerning risks and lack of knowledge (i.e. nuclear waste information), and less on more opportunistic issues like future benefits to the region from a nuclear waste storage and trust for the stakeholders involved in the decision making process.

\subsection{Crucial aspects for the younger stakeholders' acceptance of a final repository for nuclear waste}

In the three regional samples, 38\% said that the safety aspect is the most important one for considering a repository for nuclear waste. The environmental

Table 4: What do you base your opinions on?

\begin{tabular}{|c|c|c|c|c|c|c|c|c|c|c|c|}
\hline \multirow{2}{*}{ Answer } & City & \multicolumn{2}{|c|}{ Gdansk } & \multicolumn{2}{|c|}{ Elbląg } & \multicolumn{2}{c|}{ Lublin } & \multicolumn{2}{c|}{ Sub SUM } & \multicolumn{2}{|c|}{ SUM } \\
\cline { 2 - 12 } & Gender & $\mathrm{M}$ & $\mathrm{W}$ & $\mathrm{M}$ & $\mathrm{W}$ & $\mathrm{M}$ & $\mathrm{W}$ & $\mathrm{M}$ & $\mathrm{W}$ & $\mathrm{MW}$ & $\%$ \\
\hline $\begin{array}{c}\text { Trust for the } \\
\text { stakeholders }\end{array}$ & 40 & 16 & 3 & 9 & 35 & 34 & 78 & 59 & 137 & 14,9 \\
\hline $\begin{array}{c}\text { Nuclear waste dis- } \\
\text { posal opportunities }\end{array}$ & 24 & 7 & 9 & 8 & 31 & 29 & 64 & 44 & 108 & 11,7 \\
\hline Lack of knowledge & 86 & 54 & 13 & 28 & 21 & 67 & 120 & 149 & 269 & 29,2 \\
\hline Unease with risks & 111 & 49 & 14 & 51 & 32 & 93 & 157 & 193 & 350 & 38,0 \\
\hline Miscellaneous & 19 & 6 & 4 & 1 & 11 & 15 & 34 & 22 & 56 & 6,1 \\
\hline Total & 280 & 132 & 43 & 97 & 130 & 238 & 453 & 467 & 920 & 100 \\
\hline
\end{tabular}

Table 5: What aspects are most important for acceptance?

\begin{tabular}{|l|c|c|c|c|c|c|c|c|c|c|c|}
\hline \multirow{2}{*}{ Answer } & City & \multicolumn{2}{|c|}{ Gdansk } & \multicolumn{2}{|c|}{ Elbląg } & \multicolumn{2}{c|}{ Lublin } & \multicolumn{2}{c|}{ Sub SUM } & \multicolumn{2}{|c|}{ SUM } \\
\cline { 2 - 14 } & Gender & M & W & M & W & M & W & M & W & MW & $\%$ \\
\hline Safety aspect & 87 & 5 & 26 & 61 & 97 & 166 & 210 & 232 & 442 & 38,0 \\
\hline Environmental aspect & 63 & 2 & 17 & 45 & 63 & 119 & 143 & 166 & 309 & 26,5 \\
\hline $\begin{array}{l}\text { As far as possible } \\
\text { from home }\end{array}$ & 59 & 5 & 14 & 44 & 45 & 97 & 118 & 146 & 264 & 22,7 \\
\hline $\begin{array}{l}\text { Methods and } \\
\text { techniques }\end{array}$ & 19 & & 9 & 4 & 25 & 52 & 53 & 56 & 109 & 9,4 \\
\hline Economic growth & 7 & & 6 & 3 & 6 & 7 & 19 & 10 & 29 & 2,5 \\
\hline Miscellaneous & 1 & & 1 & & 5 & 4 & 7 & 4 & 11 & 0,9 \\
\hline \multicolumn{1}{|c|}{ Total } & 236 & 12 & 73 & 157 & 241 & 445 & 550 & 614 & 1164 & 100 \\
\hline
\end{tabular}


aspect was seen as the second most important factor with a total answer frequency of $27 \%$. The third most important factor was whether the localization of the disposal facility should be as far from home as possible which was put forward by $23 \%$. These three reasons have an explanatory power of nearly seven eights, or more exactly $87 \%$, see Table 5 for further detail.

\subsection{The information channels that are prioritised by the younger stakeholders}

Data on the preferences of younger stakeholders on communication channels and information processes with regard to nuclear waste is presented in Table 6 .

The respondents also gave a lot of suggestions for possible improvements and developments regarding the shape and form of information in the areas of decommissioning of nuclear facilities and management of nuclear waste:

- It may be appropriate to notice that the alternative to participate in project groups (collective learning) was the most popular alternative that was suggested in $29 \%$ of the cases.

- The alternative of producing a film was mentioned in $19 \%$ of the cases.

- The suggestion to plan, organise and conduct exhibitions was given in $16 \%$ of the cases.

- The alternative to use, create and construct websites was given in $15 \%$ of the case.

- The suggestion to use "power point" presentations was suggested in $13 \%$ of the cases.

- The alternative to make a theatre play was an option for $4,9 \%$ of the respondents.

\section{Some tentative conclusions}

The data presented above supports some tentative conclusions on the values of younger European citizens regarding decommissioning of older nuclear facilities and disposal of the nuclear waste. The main findings are as follows:

Table 6: Channels for communication preferred by younger stakeholders.

\begin{tabular}{|c|c|c|c|c|c|c|c|c|c|c|c|}
\hline \multirow{2}{*}{ Answer } & City & \multicolumn{2}{|c|}{ Gdansk } & \multicolumn{2}{|c|}{ Elbląg } & \multicolumn{2}{c|}{ Lublin } & \multicolumn{2}{c|}{ Sub SUM } & \multicolumn{2}{|c|}{ SUM } \\
\cline { 2 - 14 } & Gender & $\mathrm{M}$ & $\mathrm{W}$ & $\mathrm{M}$ & $\mathrm{W}$ & $\mathrm{M}$ & $\mathrm{W}$ & $\mathrm{M}$ & $\mathrm{W}$ & MW & $\%$ \\
\hline Project work & 55 & 3 & 19 & 43 & 71 & 141 & 145 & 187 & 232 & 29,3 \\
\hline \multicolumn{2}{|c|}{ Exhibitions } & 26 & 5 & 7 & 23 & 41 & 83 & 74 & 111 & 185 & 16,3 \\
\hline $\begin{array}{c}\text { Power-Point } \\
\text { presentation }\end{array}$ & 28 & 3 & 7 & 18 & 32 & 56 & 67 & 77 & 144 & 12,7 \\
\hline Create web pages & 29 & 3 & 13 & 29 & 39 & 54 & 81 & 86 & 167 & 14,7 \\
\hline \multicolumn{2}{|c|}{ Theatre } & 6 & 1 & 4 & 13 & 8 & 24 & 18 & 38 & 56 & 4,9 \\
\hline Film & 58 & 4 & 17 & 36 & 28 & 71 & 103 & 111 & 214 & 18,9 \\
\hline Other & 4 & & 2 & 1 & 13 & 15 & 19 & 16 & 35 & 3,1 \\
\hline \multicolumn{2}{|c|}{ Total } & 206 & 19 & 69 & 163 & 232 & 444 & 507 & 626 & 1133 & 100 \\
\hline
\end{tabular}


- Younger citizens tend to favour long term sustainable energy sources, e.g. hydropower and windmills, before non-sustainable techniques, e.g. nuclear power and carbon based fossil fuels.

- Younger citizens tend to base their values on safety and environmental aspects, while other aspects like contribution to future economic growth in the society and development of technological processes are less influential on the values.

- Younger citizens have a limited trust, or scepticism, concerning the capabilities and skills of the contemporary decision makers to develop and present prudent, sound and long term sustainable management of nuclear waste from decommissioning of nuclear facilities.

- Younger citizens tend to refer to a deficit of knowledge, information and debate as a base for their judgement of the decision makers' skills, determination and credibility on this topic.

- Younger citizens can demonstrate major and well defined suggestions on how more information can be made accessible to the general public. They are also able to present a wide spectrum of methods, ways and modes to include younger people in the topic and the related democratic processes.

- Younger citizens have the propensity to prioritize aspects such as safety and environmental questions above financial aspects and economic growth as criteria for distribution and allocation of different sources of energy.

\section{Findings and recommendation: a synthesis}

Our study supports the statement that the younger generation is likely to support not only the general Polluter Pays Principle and the major thoughts in the European environmental codex, but are also interested in participating and giving contributions to open democratic processes regarding ways in which the nuclear waste of today shall be managed. They are open to communication and are accepting a wide selection of communication channels. Hence, the younger stakeholders can fulfil their part of the Extended Polluter Responsibility (EPR).

Interestingly, and in contrast to results obtained previously for older persons, we have found no significant differences between the sexes in the values and attitudes.

An early entrance in the planning phase is normally seen as one prerequisite for a successful dismantling and decommissioning of permanently closed nuclear facilities. Likewise, an early entrance of the younger citizens in the planning for dismantling of older nuclear facilities and management of nuclear waste is likely to have a positive effect on the accuracy of the cost calculations of the future financial liabilities, and thereby also on the robustness of the entire process.

Hence, it appears reasonable to encourage that younger citizens already at an early stage engage in an open and democratic decision process concerning decommissioning of nuclear facilities and the associated waste management. This will improve the planning process and at the same time the quality of the cost calculations. This will, in turn, contribute to better use of eared-marked 
resources for decommissioning and thereby reduce the risk that future generations might face a deficiency in terms of a deviance between actual costs and funds [14].

Conversely, failure to involve the younger citizens in the process may result in cost driving activities, since a longer period of time will be needed in order to go through the decommissioning process. Furthermore, a prolonged process will also increase the total detriment from health, safety and environmental perspectives. Thus, failure to include younger stakeholder is a potential cost riser.

The presented data demonstrates that younger stakeholders can be successfully included in the process if appropriate channels for communication are selected based on the preferences of this stakeholder group. Thus, risk communication is not only a question of the content but also a question of choosing appropriate channels for communication. The possibilities for fruitful communication can be enhanced if the nuclear waste information is based on comprehensive didactic methods specially designed for younger age groups.

\section{References}

[1] Padilla, E., Intergenerational equity and sustainability. Ecological Economics 41 (2002) 69-83.

[2] Lindskog, S. \& Sjöblom, R., Radiological, technical and financial planning for decommissioning of small nuclear facilities in Sweden. Proceedings of the 12th International Conference on Environmental Remediation and Radioactive Waste Management, ICEM2009, October 11-15, 2009, Liverpool, UK.

[3] Espejo, R., Structure for Transparency in Nuclear Waste Management, Comparative Review of the Structures for Nuclear Waste Management in France, Sweden and the UK. SKI* Report 2003:26, November 2002, p. 30.

[4] Andersson, K., et al, Design and Evaluation of Public Hearings for Swedish Site Selection, A Report from the RISCOM II Project. SKI* Report 2003:3. August, 2003.

[5] Andersson, K., et al., Public Values and Stakeholder Involvement - A New framework for Performance Assessment, A Report from the RISCOM II Project. SKI* Report 2004:24. October, 2003.

[6] Elam, M. and Sundqvist G., Stakeholder Involvement in Swedish Nuclear Waste Management. SKI* Report 2007:02. September, 2006.

[7] Laraia, M. \& McIntyre, P. J., responsible officers; Cato A., Lindskog S. \& Sjöblom. R. et al contributors. Decommissioning of research reactors and other small facilities by making optimal use of available resources. IAEA Report Series 463, Vienna 2008.

[8] Geological Repositories: Political and Technical Progress. OECD, Nuclear Energy Agency (NEA). OECD 2005, pages 61-65.

[9] Frantisek, O., et al., Methodology for description and evaluation of cost profiles and cost structure during transition period. SKI* Report 2008:38. May, 2008 
[10] Sjöberg, L., Attityd till slutförvar av använt kärnbränsle. (Attitudes to a final repository for spent nuclear fuel. In Swedish. Swedish Nuclear Fuel and Waste Management Company, SKB. SKB Report R-08-119. September 2008.

[11] Skolungdomars inställning till slutförvar av kärnavfall. (The attitude of students to final storage of nuclear waste. In Swedish). The Regional Council of Kalmar. Kalmar, Sweden, 2007.

[12] Tyszkiewicz, B. and Labor, B., A Survey of Younger Citizens Values towards Decommissioning and Dismantling of Older Nuclear Facilities in a European Perspective. SKI* Report 2008:52. June, 2008.

[13] Tyszkiewicz, B. and Labor, B., On Younger Stakeholders and Decommissioning of Nuclear Facilities. SSM* Report 2009:32. August, 2009.

[14] Lindskog, S., Cato, A. \& Sjöblom, R., Estimations of costs for dismantling, decommissioning and associated waste management of nuclear facilities, and associated impact on decision processes, functioning of markets and the distribution of responsibilities between generations. Environmental Economics II, 28-30 May 2008, Cadiz, Spain. WIT Transactions on Ecology

* SKI $=$ Swedish Nuclear Power Inspectorate, now Swedish Radiation Safety Authority (SSM). Reports are available at www.ssm.se. 